Goldschmidt 2021 Abstract

https://doi.org/10.7185/gold2021.5446

\section{Mapping contaminant distributions and sources across heterogeneous landscapes through remotely sensed metal bioaccumulation}

\author{
KATHLEEN GRANT ${ }^{1}$, K. DANA CHADWICK ${ }^{2,3}$, PHILIP G. \\ BRODRICK $^{4}$, JOSHUA WEST ${ }^{1}$, COREY LAWRENCE ${ }^{5}$, \\ NICOLA FALCO ${ }^{6}$ AND KATE MAHER ${ }^{2}$ \\ ${ }^{1}$ University of Southern California \\ ${ }^{2}$ Stanford University \\ ${ }^{3}$ University of Texas at Austin \\ ${ }^{4}$ California Institute of Technology \\ ${ }^{5}$ Geosciences and Environmental Change Science Center \\ ${ }^{6}$ Lawrence Berkeley National Laboratory \\ Presenting Author: kdennist@usc.edu
}

Anthropogenic activities have generated high accumulations of heavy metal concentrations in soils around the world. Heavy metals released from mines pose hazardous threats to human, animal, and plant populations in the immediate area and further downstream. However, it remains challenging to locate, and identify the spatial extent of, metal mobilization and consequent bioavailability from both anthropogenic and natural sources. A variety of studies have shown that metal contents within soil profiles are controlled by the characteristics of the local vegetation. Different soil metal concentrations have been associated with different types of vegetation, and the vertical distributions of metals respond to changing vegetation. These linkages between vegetation and the presence of contaminants provide a potential window to detect subsurface contamination via vegetation properties, if it is possible to remotely detect metal bioaccumulation or metal tolerant species.

Airborne visible to shortwave infrared (VSWIR) imaging spectroscopy, also known as hyperspectral data, has become increasingly available in recent years. These high spatial and spectral resolution data have enabled the mapping of vegetation characteristics over large areas; however, the potential to utilize foliar traits, that can be estimated with VSWIR datasets, to infer soil properties, including toxicity, remains largely unexplored. Here, we utilized an extensive dataset of foliar and soil metal concentrations from samples collected contemporaneously with VSWIR data from the National Ecological Observation Network's Airborne Observation Platform to map foliar metal concentrations across four headwater catchments in Colorado that encompass a range in past mining activity. Maps of foliar and soil concentrations enabled us to indirectly observe that abandoned mines act as point sources of increased cadmium $(\mathrm{Cd})$, copper $(\mathrm{Cu})$, nickel $(\mathrm{Ni})$, and zinc $(\mathrm{Zn})$ concentrations in vegetation. Determining the link between foliar chemistry and the soil depth distribution of metals provides an indirect method to visualize the spatial extent of metal bioaccumulation, and offers insights into contamination sources that can be used as a benchmark for modeling expected contamination spread. Understanding the spatial distribution of metal contaminates through high-resolution vegetation characterization has the potential to contribute to large-scale remediation efforts and water quality protection through various methods including phytoremediation. 